\title{
VIBRATORY STIMULATION OF MUSCLES AND STRETCH REFLEX
}

\author{
Saburo Homma, Hideo Kobayashi and Shiroh Watanabe \\ Department of Physiology, School of Medicine, \\ Chiba University, Chiba, Japan
}

It is well known that a high frequency low amplitude vibration of muscles is an effective stimulus for the selective activation of the primary endings of muscle spindles (GRANiT and HeNATSCH, 1956; Bessou and LAPORTE, 1962 ; Brown, EngBerg and Matthews, 1967). The repetitive discharges of Ia afferents from the vibrated muscle is transmitted monosynaptically to homonymous motoneurons driving them also into repetitive discharge (HoMмA, IshikAWA and WatANABe, 1967 ; Matthews, 1966; HAGBARTH and EkLund, 1966). When the amplitude of vibration is relatively high and the frequency of stretch under ca. $10 \mathrm{cps}$ motoneurons are fired by each stretch of a repetitive train. Beyond this stretch rate motoneurons do, however, exhibit frequency limiting behaviour (HOMMA, IsHIKAWA and STUART, 1969). In other words there is a "preferred frequency" of discharge above which the motoneuron will not fire in response to more intense Ia afferent bombardment. Similar behaviour is exhibited in reflex response to a relatively static increase in muscle tension (ROBERTS, 1967) or in response to a lower amplitude vibration in which latter case the "preferred" firing rate is not attained until the vibration frequency is increased considerably beyond $10 \mathrm{cps}$ (HOMMA, ISHIKAWA and WATANABE, 1967).

Previously we have shown that the preferred 6 to $13 \mathrm{imp} / \mathrm{sec}$ firing rate of gastrocnemius motoneurons is evoked at a minimal amplitude of vibration when the vibration frequency is near $100 \mathrm{cps}$. Thus, $100 \mathrm{cps}$ could be termed the "optimal frequency" of vibration for gastrocnemius motoneurons (НоммA, ISHIKAWA and WATANABE, 1967). By plotting the minimum amplitude ( $\Delta \mathrm{L}$ on $\mathrm{Y}$ axis) of vibration necessary to evoke the preferred firing rate against a wide range of vibration ( $\mathrm{f}$ on $\mathrm{X}$ axis), it is possible to reveal a "response area" profile for each motoneuron. This report is concerned with the $\Delta \mathrm{L}-\mathrm{f}$ response area and optimal frequency characteristic of gastrocnemius motoneurons and the extent to which such parameters of vibrator responsiveness

Received for publication November 24, 1969

本間三郎，小林英夫，渡部士郎 
could be altered by post-tetanic potentiation, concomitant stretch of a synergist and by stimulation of antagonistic afferents. The responses of Ia afferents to vibration were also contrasted to motoneuron response.

\section{METHODS}

Experiments were performed on 35 adult cats, anesthetized with a solution of alpha chloralose and urethan $(5 \mathrm{cc} / \mathrm{Kg}$ i.p. of $1 \%$ alpha chloralose and $10 \%$ urethan in $0.9 \%$ saline). A lumbo-sacral laminectomy was performed and ventral rootlets $L_{7}$ to $S_{1}$ separated from the spinal cord. All nerves to the tail, hip and hind limbs were cut except those innervating medial gastrocnemius and the lateral gastrocnemius and soleus. Taking extreme care not to compromise the circulation, tendons of these two muscles were cut and separated from each other in such a way that they could be stretched separately. The tendon of the muscle under study was attached by a steel hook to an electromagnetic vibrator. The vibrator system consisted of a solid state function generator (Model FG-108T, NF Circuit Block Design Co., Ltd., Tokyo), a photoelectric gate device, a power amplifier and a moving coil type muscle puller (WATANABE, KoBAYASHi and Homma 1970).

Conventional techniques were employed for recording from the functionally isolated ventral root filaments of gastrocnemius. Units were identified by their accelerated response to a brief manual stretch of the homonymous muscle (HOMMA, KANO and TAKANo 1962). After each unit was identified the tendon of the homonymous muscle was attached to the muscle puller. Minimum vibration amplitude $(\Delta \mathrm{L})$ necessary to evoke the preferred firing rate was then determined for vibration frequencies ranging from 20 to $180 \mathrm{cps}$. For this test 1 second periods of vibration were applied to the muscles at 2 seconds intervals and the responses photographed from the face of an oscilloscope. Data analysis was greatly facilitated in later experiments by use of an electronic counter and storage oscilloscope. For post-tetanic potentiation of the motoneuron under study or activation of antagonistic afferents, the appropriate muscle nerve was tetanized at $100 \mathrm{c} / \mathrm{sec}$. Square wave pulses of $0.1 \mathrm{msec}$ duration were used and stimulus strength adjusted to $\times 2$ the threshold for muscle contraction. At the conclusion of each experiment, dorsal rootlets $L_{6}$ to $S_{2}$ were severed. Response area and optimal frequency characteristics could then be determined for a certain number of gastrocnemius Ia afferents.

\section{RESULTS}

\section{Muscle vibration and Ia discharge}

It is well known that Ia afferents from a de-efferented muscle can respond to each fixed-amplitude stretch in a repetitive vibratory train up to rates of $350 \mathrm{cps}$ (BIANCONI and VAN DER MEULEN, 1963). In our present study a corollary form of behaviour was routinely noted by determining the stretch amplitude necessary to elicit an arbitrarily fixed la firing rate of $20 \mathrm{imp} / \mathrm{sec}$ as the vibration frequency was increased over a broad range. A typical set of responses for a Ia afferent from the gastrocnemius is shown in FIG. 1 and the $\Delta \mathrm{L}$-f curve (crosses) plotted in FIG. 2. It is quite clear that as the vibration frequency is increased there is a gradual reduction and then an increase in $\Delta \mathrm{L}$, the optimal frequency being near $100 \mathrm{cps}$. Also shown in FIG. 2 is 

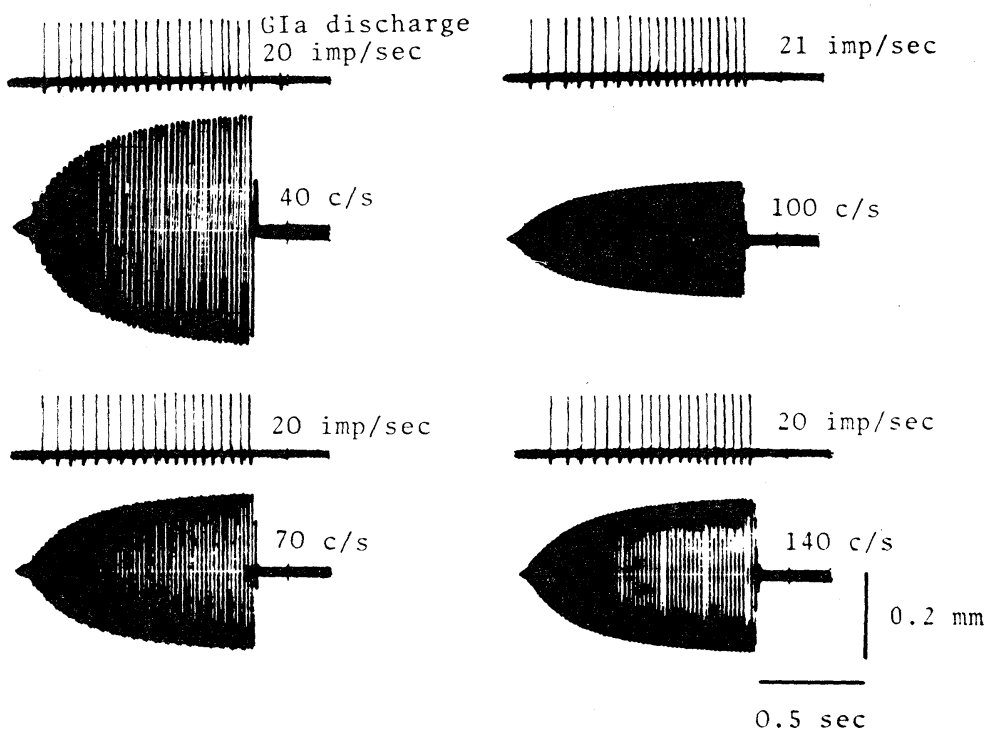

FIG. 1. Frequency-amplitude characteristics (lower trace) of vibration necessary to maintain Ia afferent discharge (upper trace) at an arbitrarily fixed firing rate of $20 \mathrm{imp} / \mathrm{sec}$.

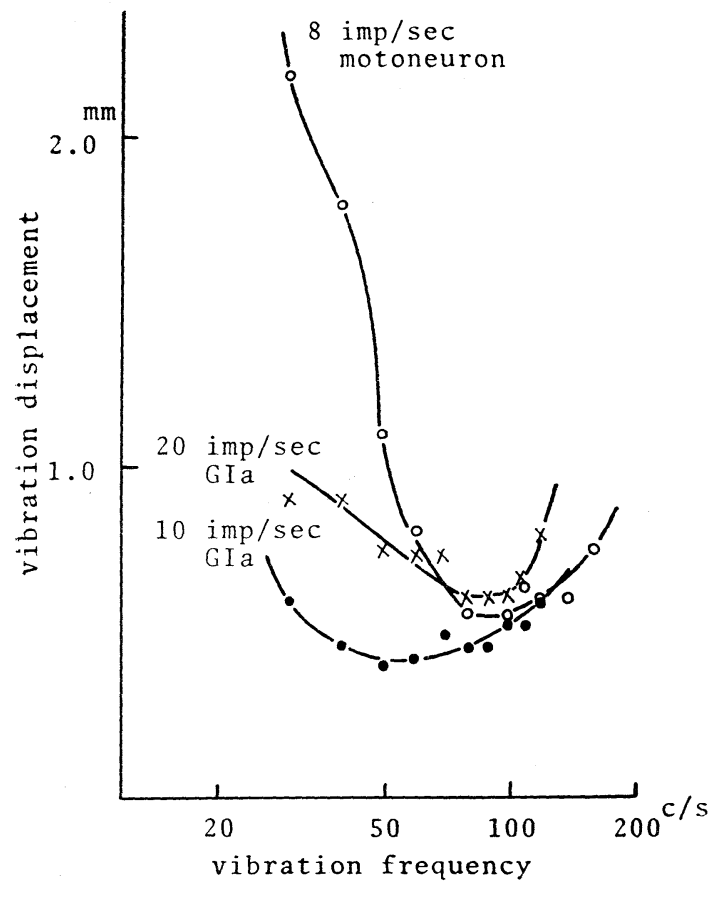

FIG. 2. Comparison of $\Delta \mathrm{L}-\mathrm{f}$ curves for a gastrocnemius motoneuron (open circle) and a Ia afferent from the gastrocnemius (crosses and filled circles). For further explanation see text. 
the $\Delta \mathrm{L}-\mathrm{f}$ curve for the same unit for an arbitrarily fixed firing rate of 10 $\mathrm{imp} / \mathrm{sec}$. To sustain this lower firing rate, a lesser $\Delta \mathrm{L}$ was required at all vibration frequencies and, further, the optimal frequency for vibration was reduced to near $50 \mathrm{cps}$.

\section{Muscle vibration and motoneuron discharge}

The repetitive discharge of Ia afferents from the vibrated muscle is transmitted monosynaptically to the homonymous motoneuron driving them also into repetitive discharge. Motoneuron does not, however, exhibit discharge rate over a preferred frequency as already described in the introduction. In FIG. 3, the preferred frequency for the gastrocnemius motoneuron was $6 \mathrm{imp} / \mathrm{sec}$. It is seen that as the vibration frequency is increased there is a reduction and then increase in $\Delta \mathrm{L}$, the optimal frequency being near $100 \mathrm{c} / \mathrm{s}$.

FIG. 2 further shows the L-f curve for another gastrocnemius motoneuron. The preferred frequency for this unit was $8 \mathrm{imp} / \mathrm{sec}$. As vibration frequency was increased, the $L$ necessary to maintain firing at the preferred rate reduced from $2.2 \mathrm{~mm}$ at $30 \mathrm{cps}$ vibration to near $0.25 \mathrm{~mm}$ at 80 to $100 \mathrm{cps}$ vibration
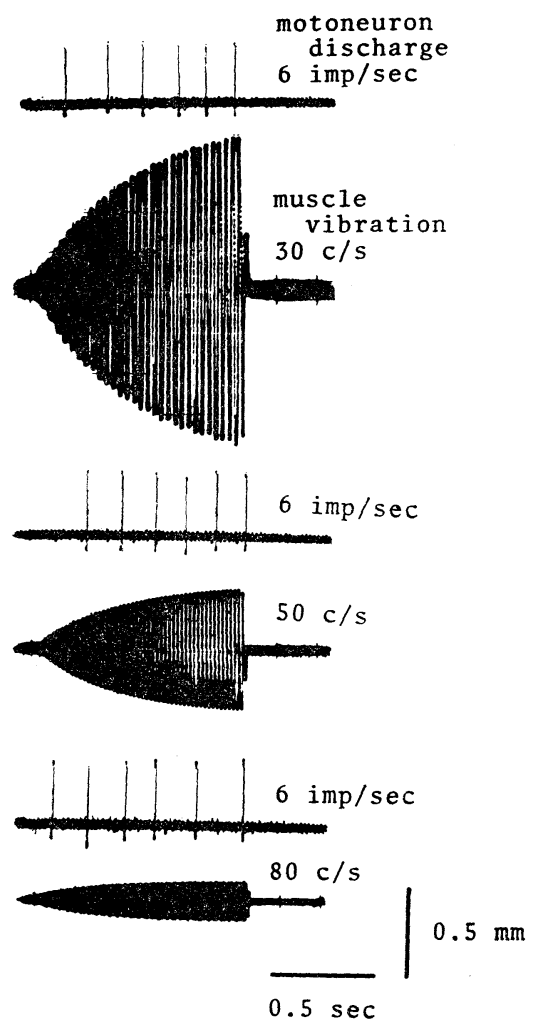

FIG. 3. Frequency-amplitude characteristics of vibration (lower traces) necessary to maintain a gastrocnemius motoneuron firing at its preferred rate of 6 $\mathrm{imp} / \mathrm{sec}$ rate (upper trace). 
(FIG. 2). Further increase in the vibration frequency to $120 \mathrm{cps}$ required a $\Delta \mathrm{L}$ of $0.6 \mathrm{~mm}$ to maintain the preferred frequency.

In FIG. 2 the area above each $\Delta$ L-f curve can be termed the "response area" in that any combination of $\Delta \mathrm{L}$ and $\mathrm{f}$ within this area involves a vibratory stimulus greater than that required for the preferred firing rate of motoneurons or for the arbitrarily fixed rate of Ia afferents. For both afferent (i.e. at $20 \mathrm{imp} / \mathrm{sec}$ ) and efferent discharge the area is greatest near the optimal vibration frequency and drops off most dramatically at vibration frequencies under $50 \mathrm{cps}$. Also of interest in FIG. 2 is the wide disparity in $\Delta \mathrm{L}$ for Ia and motoneuron discharge at $30 \mathrm{cps}$ vibration in contrast to the slight difference in the 80 to $100 \mathrm{cps}$ optimal frequency range.

\section{Post-tetanic potentiation.}

To study the effect of post-tetanic potentiation on vibrator responsiveness, a standard $\Delta \mathrm{L}$-f curve was first generated for each motoneuron. Next the homonymous muscle nerve was tetanized for 1 minute and $\Delta \mathrm{L}-\mathrm{f}$ points measured for 3 vibration frequencies. Since the facilitatory effect of post-tetanic potentiation on motoneuron decays exponentially in some tens of seconds it was not possible to secure information over a broad range of stretch fre-

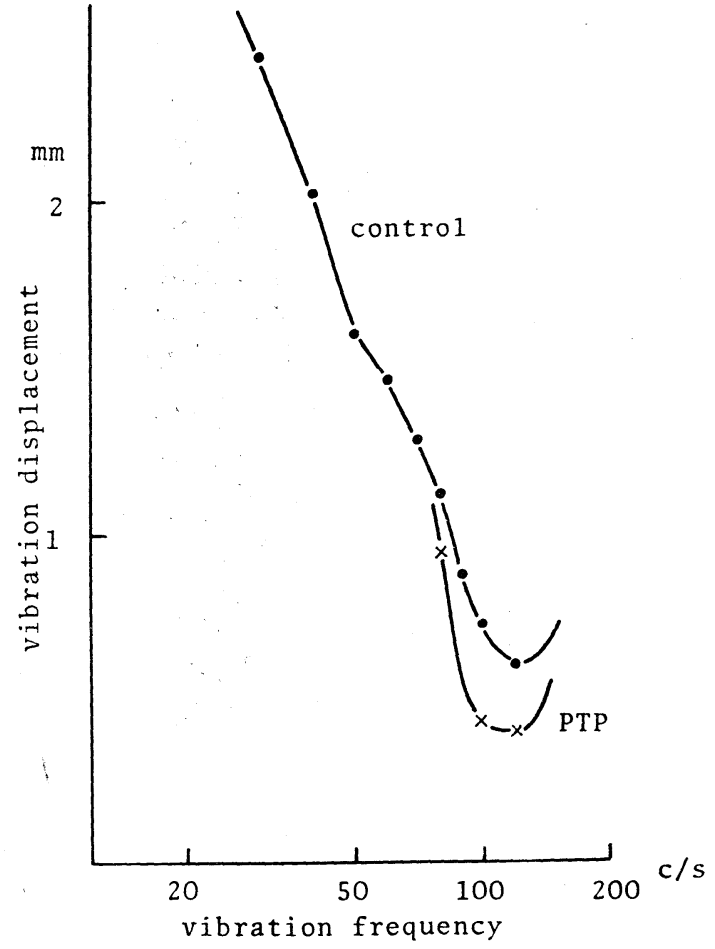

FIG. 4. The $\Delta$ L-f curve of a gastrocnemius motoneuron measured at preferred firing rate of $7 \mathrm{imp} / \mathrm{sec}$ before (filled circles) and after (crosses) a period of post-tetanic potentiation. For further explanation see text. 
quencies. Nonetheless, there was a clear indication that the major facilitatory effect of post-tetanic potentiation of the $\Delta \mathrm{L}-\mathrm{f}$ curve was expressed near the optimal frequency (FIG. 4).

\section{Antagonistic afferent stimulation}

FIG. 5 shows the typically pronounced influence of antagonist afferent stimulation on the $\Delta \mathrm{L}-\mathrm{f}$ curve of a gastrocnemius motoneuron. For this test the standard $\Delta \mathrm{L}$-f curve was first generated. Next the lateral peroneal nerve was tetanized at $100 \mathrm{c} / \mathrm{sec}$. During such tetanization, $\Delta \mathrm{L}-\mathrm{f}$ curve was again obtained for the same motoneuron. At no vibration frequency was it possible to evoke a motoneuron discharge at available amplitudes. By reducing the repetitive rate of the tetanizing stimulus to $15 \mathrm{c} / \mathrm{s}$ and $5 \mathrm{c} / \mathrm{s}$ it was however, possible to generate the $\Delta \mathrm{L}$-f curves shown in FIG. 5 . For each vibration frequency a greater $\Delta \mathrm{L}$ was necessary to elicit the preferred firing frequency following stimulation of the antagonistic nerve. This increase in $\Delta \mathrm{L}$ was minimal near the optimal vibration frequency and maximal at the slowest vibration frequency employed. In some cases $15 \mathrm{c} / \mathrm{s}$ stimulation of the lateral peroneal nerve also shifted the optimal frequency slightly to the left.

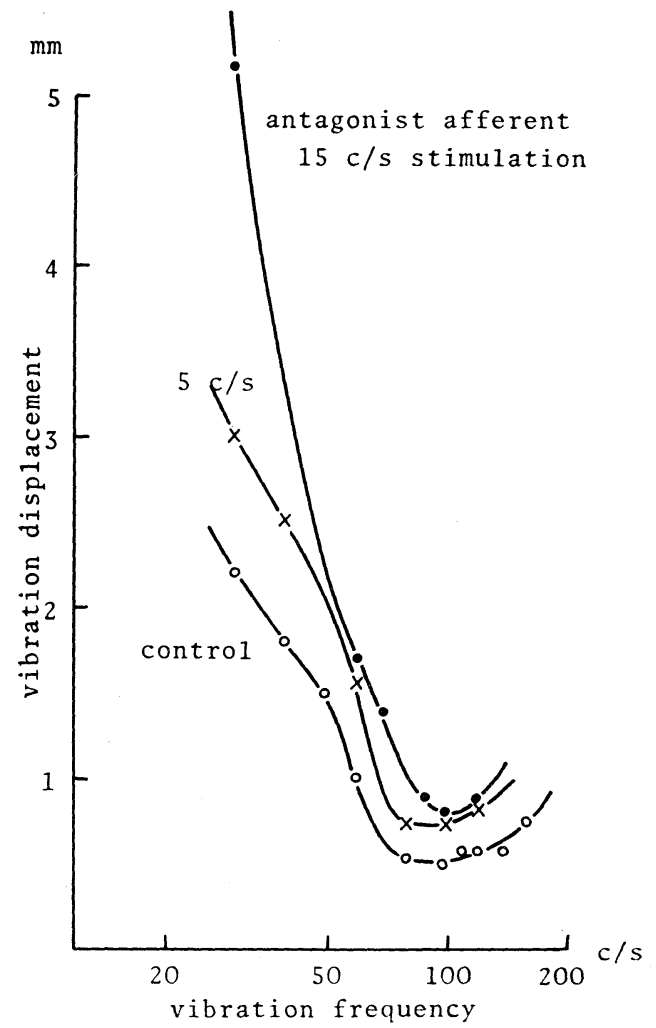

FIG. 5. The $\Delta$ L-f curve of a gastrocnemius motoneuron measured at preferred firing rate of $8 \mathrm{imp} / \mathrm{sec}$ before (open circle) and during $5 \mathrm{c} / \mathrm{sec}$ (crosses) and $15 \mathrm{c} / \mathrm{sec}$ (filled circle) repetitive stimulation of the lateral peroneal nerve. 
5. Effect of synergistic muscle stretch.

FIG. 6 shows the control $\Delta$ L-f curve for a gastrocnemius motoneuron and the changes induced by a concomitant $3 \mathrm{~mm}$ stretch of the synergist soleus muscle. The increased $\Delta \mathrm{L}$ necessary to maintain the preferred firing rate over the entire vibration frequency range was a consistent finding. Less consistent were the effects of a further increase in the synergist stretch. For 14 motoneurons there was an unfailing facilitation in the $\Delta$ L-f profile. For 6 motoneurons however the facilitatory effect was reversed during a strong stretch of the synergist and at all vibration frequencies the preferred firing rate could only be maintained by increasing $\Delta \mathrm{L}$ values above those used in the control curve.

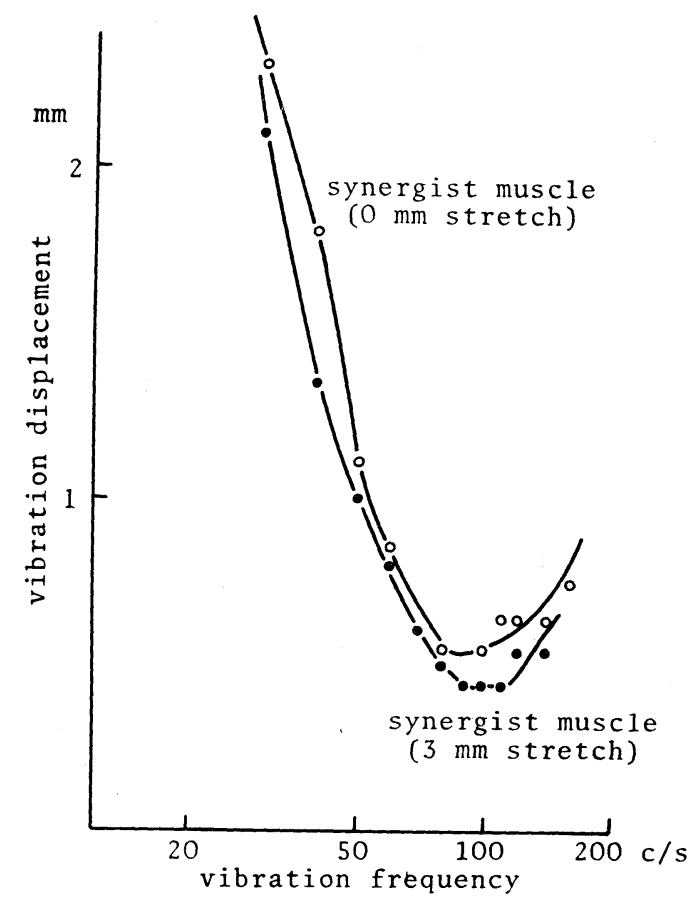

FIG. 6. The $\Delta$ L-f curve of a gastrocnemius motoneuron at preferred firing rate of $8 \mathrm{imp} / \mathrm{sec}$ (open circles) and during (filled circles) concomitant stretching of the soleus muscle.

At this stage in our experiments we have not explored in detail the extent of interaction between the opposite effects exerted on the gastrocnemius $\Delta$ L-f curve by afferent input from antagonists and synergists. That such interaction exists is however revealed by the data shown in Fig. 7. Whereas no motoneuron discharge could be elicited following $100 \mathrm{c} / \mathrm{sec}$ stimulation of the peroneal nerve, a $\Delta$ L-f curve could be generated even after such stimulation if there was a concomitant stretch of the soleus muscle. The inhibitory effect did, however, predominate in the latter case, but it is difficult 


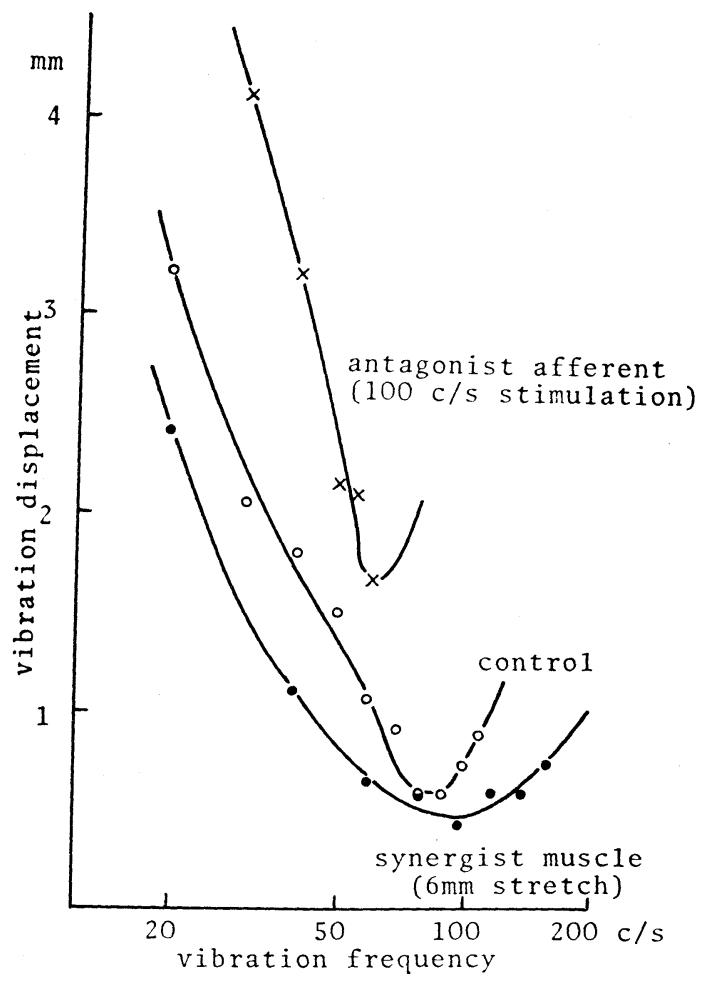

Fig. 7. The $\Delta \mathrm{L}$-f curve of a gastrocnemius motoneuron at preferred firing rate of $8 \mathrm{imp} / \mathrm{sec}$ before (open circle) and during (filled circle) concomitant stretching of the soleus muscle. The $\Delta$ L-f curve generated during 100 $\mathrm{c} / \mathrm{sec}$ stimulation of the lateral peroneal nerve with concomitant stretching of soleus muscle (filled circle) is also shown.

to equate afferent volleys evoked by electrical and natural stimulation. More important is the clear cut evidence of interaction between these opposing stimuli. Furthermore FIG. 7 clearly shows that the facilitatory effect of the synergistic muscle stretch shifts the optimal vibration frequency to the right and results in a broadening and downward shift of the $\Delta \mathrm{L}$-f curve. The inhibitory effect of antagonistic afferent stimulation, on the other hand, shifts the frequency to the left and results in a narrowing and upward shift of the response area curve.

\section{DISCUSSION}

The response of Ia afferents and motoneurons to low amplitude high frequency vibration of the homonymous muscle is quite different. Even without fusimotor activation, Ia afferents can follow individual stretches in a repetitive vibration train up to $350 \mathrm{cps}$ (BIANCONI and VAN DER MEUlen, 1963). In contrast the peak firing rate achieved by motoneurons rarely exceeds $13 \mathrm{imp} / \mathrm{sec}$. Frequency limiting behaviour is exhibited by motoneurons in response to relatively high amplitude of repetitive (HoMmA, IsHIKAWA and STUART, 1969) and maintained (ROBERTs, 1967) stretch. In the latter case the 
peak firing rate achieved by the motoneuron has been termed the "preferred frequency". In previously reported work (HOMMA, IsHIKAWA and WATANABE, 1967) we measured the minimum vibratory amplitude $(\Delta \mathrm{L})$ needed to evoke the preferred rate for gastrocnemius motoneurons over a wide (20 to $180 \mathrm{cps}$ ) range of vibration frequencies (f). As vibration frequency (f) was increased, the required $\Delta \mathrm{L}$ first diminished then increased. The behaviour could be described conveniently in the form of $\Delta \mathrm{L}-\mathrm{f}$ curve, the area above the curve representing a "response area". The mininimal $\Delta \mathrm{L}$ needed to sustain preferred firing was associated with a vibration frequency near $100 \mathrm{cps}$, the "optimal frequency" for vibration.

In the present report $\Delta \mathrm{L}$-f curves were contrasted over the same vibration frequency range for gastrocnemius motoneurons maintaining their preferred firing rate and for Ia afferents from gastrocnemius firing at arbitrarily fixed rates of 10 and $20 \mathrm{imp} / \mathrm{sec}$. As shown in FIG. 2, the optimal frequency of vibration was quite similar for afferent (at $20 \mathrm{imp} / \mathrm{sec}$ ) and efferent unit as were the $\Delta \mathrm{L}$ values associated with this optimal frequency. The further vibration frequency was removed from the optimal frequency, the greater became the difference between afferent and efferent $\Delta \mathrm{L}$ values. Near $20 \mathrm{cps}$ for example over $2 \mathrm{~mm}$ of stretch was required to maintain preferred motoneuron firing rate whereas less than $1 \mathrm{~mm}$ of stretch was required to sustain $20 \mathrm{imp} / \mathrm{sec}$ firing of Ia afferents. At first glance it might appear that the difference in the profile of $\Delta \mathrm{L}$-f curves for the Ia afferents and the motoneurons they excite, could be explained by the likelihood that group II becomes manifest in the high amplitude-low frequency range of vibration (BROWN, ENGBERG and MATthews, 1967). Viewed in this light, maintenance of the preferred motoneuronal firing rate at slower vibration frequencies would require an increased vibration amplitude and intense Ia discharge to offset the group II effect, which conventionally is considered inhibitory for the stretch reflex (BIANCONI, GRANIT and ReIs, 1963). However there is recent evidence that group II as well as Ia input contributes to the autogenetic excitation of the stretch reflex (MatThews, 1969). Also unclear is the extent to which Ib input must be considered. While the autogenetic inhibitory effect of Ib input on the stretch reflex has not been questioned, there is little information concerning the extent to which Ib afferents would be activated by a high (greater than $1 \mathrm{~mm}$ ) amplitude vibration of low (less than $50 \mathrm{cps}$ ) frequency. Indirect evidence on the response of $\mathrm{Ib}$ afferents to single transient stretches (Stuart, Mosher, GERLACH and Reinkin, 1969) suggests that Ib input would become manifest under these conditions. Further speculation is however unwarranted until $\Delta \mathrm{L}$-f curves have been generated for Ib afferents.

The concept of a " response area" must be emphasized in the meaning that every point above the $\Delta \mathrm{L}$-f curve indicates vibration parameters which are more 
than sufficient for the generation of motoneuron discharge at the preferred firing rate. In many ways the concept is similar to that of an auditory sensation area. Facilitation in the form of increased vibrator responsiveness was indicated by a broadening and downward shift of the $\Delta \mathrm{L}$-f curve to the right. This indicated an increase in the response area and a shift in the optimal frequency of vibration to a higher frequency. Such effects were evident after post-tetanic potentiation and during stretch of a synergist muscle. Reverse inhibitory effects were noted by generating $\Delta \mathrm{L}-\mathrm{f}$ curves before and during stimulation of antagonistic afferents. These changes suggest that the use of vibration for measurements of the $\Delta \mathrm{L}-\mathrm{f}$ curves, response area and optimal frequency provide an important new tool for testing motoneuron excitability and stretch reflex efficacy in both man and experimental animals.

\section{SUMMARY}

1. Firing patterns of Ia afferents and motoneuron efferents were recorded while subjecting homonymous de-efferented triceps surae muscle to vibration applied longitudinally to the tendon.

2. The amplitude of vibration $(\Delta \mathrm{L})$ necessary to elicit the preferred firing rate of each motoneuron was noted over a wide range (20 to $180 \mathrm{cps}$ ) of vibration frequencies (f). This permitted the plotting of a $\Delta \mathrm{L}-\mathrm{f}$ curve for each motoneuron, the area above the curve being termed the "response area" and the frequency associated with the minimal $\Delta \mathrm{L}$ being termed the "optimal frequency" of vibration. In general preferred firing rates ranged from 6 to $13 \mathrm{imp} / \mathrm{sec}$ and the optimal frequency was near $100 \mathrm{cps}$.

3. These parameters of vibrator responsiveness were measured before and after post-tetanic potentiation. They were also measured before and during concomitant stretch of a synergist and stimulation of antagonistic afferents. The facilitatory effect of post-tetanic potentiation and stretch of the synergistic muscle resulted in a broadening and downward shift of the $\Delta \mathrm{L}$-f curve to the right. This indicated an increase in response area and shift in optimal frequency to a higher value. Reverse inhibitory effects were noted during stimulation of antagonist afferents.

4. Similar parameters were generated for Ia afferents by studying their vibrator responsiveness at arbitrarily fixed rates of 20 and $10 \mathrm{imp} / \mathrm{sec}$. The optimal frequency of vibration was quite similar for afferents $(20 \mathrm{imp} / \mathrm{sec}$ ) and efferent, as were the $\Delta \mathrm{L}$ values associated with this frequency. The further vibration frequency was removed from the optimal frequency the more pronounced became the difference in $\Delta \mathrm{L}$ requirements, far less amplitude of stretch being necessary to maintain the selected Ia firing rate. There is a discussion of mechanisms underlying the difference in profile of $\Delta \mathrm{L}-\mathrm{f}$ curves for Ia afferents and motoneurons. 
The authors wish to thank Dr. Douglas G. Stuart, Department of Physiology, College of Medicine, University of Arizona, for useful discussion and suggesting several improvements in the manuscript.

\section{REFERENCES}

Bessou, P. And Laprte, Y. Responses from primary and secondary endings of the same neuromuscular spindle of the tenuissimus muscle of the cat. Symposium on Muscle Receptors, ed. D. Barker, Hong Kong Univ. Press, Hong Kong, 105-119, 1962.

Bianconi, R., Granit, R. And Reis, D.J. The effect of extensor muscle spindles and tendon organs on homonymous motoneurons in relation to gamma-bias and curarization. Acta physiol. scand. 61: 331-347, 1964.

Bianconi, R. And VAn der Meulen, J.F. The response to vibration of the endorgans of mammalian muscle spindles. J. Neurophysiol., $26: 177-190,1963$.

Brown, M.C., Engberg, I. and Matthews, P. B. C. The relative sensitivity to vibration of muscle receptors of the cat. J. Physiol., 192: 773-800, 1967.

Granit, R. And Henatsch, H. -D. Gamma control of dynamic properties of muscle spindles. J. Neurophysiol., 19: 356-366, 1956.

GRANIT, R. AND Homma, S. The discharge to maintained stretch of spindles in slow and fast muscles of rabbit. Acta physiol. scand., 46: 165-173, 1959.

Hagbarth, K.-E. And Eklund, G. Motor effects of vibratory muscle stimuli in man. In Nobel Symposium on Muscular Afferents and Motor Control, ed. R. Granit, Almqvist and Wiksell, Stockholm, 177-186, 1966.

Homma, S., IshikAw A, K. And Stuart, D. G. Motoneuron responses to linearly rising muscle stretch. Amer. J. Phys. Med. (in press 1969), 1969.

Homma, S., Ishikawa, K. And Watanabe, S. Optimal frequency of muscle vibration for motoneuron firing. J. Chiba Med. Soc., 43: 190-196, 1967.

Homma, S., Kano, M. And TAKano, K. On phasic stretch of the annulospiral ending. Symposium on Muscle Receptors, ed. D. Barker, Hong Kong Univ. Press, Hong Kong, 125-131, 1962.

Lennerstrand, G. Position and velocity sensitivity of muscle spindles in the cat. I. Primary and secondary endings deprived of fusimotor activation. Acta physiol. scand. 73 : 281-299, 1968.

Lundberg, A. AND Winsbury, G. Selective adequate activation of large afferents from muscle spindles and Golgi tendon organs. Acta physiol. scand., 49: 155-164, 1960.

Matthews, P.B.C. The reflex excitation of the soleus muscle of the decerebrate cat caused by vibration applied to its tendon. J. Physiol, $184: 450-472,1966$.

Matthew, P.B.C. A possible function for the secondary ending of the muscle spindle. J. Physiol., 201 : 102-103, 1969.

Roberts, T.D.M. Neurophysiology of postural mechanisms. Butterworths, London, 1967.

Stuart, D. G., Mosher, C. G., Gerlach, R. L. and Reinkin, R. M. Selective activation of Ia afferents by transient stretch (in preparation, 1969).

TAKANo, K. AND Homma, S. Muscle spindle responses to vibratory stimuli at certain frequencies. Jap. J. Physiol., $18:$ 145-156, 1968.

Watanabe, S., Kobayashi, H. and Homma, S. An application of photoconductive cell for controlling transients in muscle vibration. J. Chiba Med. Soc. 45: 358-361, 1970. 